\section{Calciphylaxis in the Absence of Renal Disease: Secondary Hyperparathyroidism and Systemic Lupus Erythematosus}

\section{To the Editor:}

Calciphylaxis is a rare disorder characterized by calcification of small and medium-size arteries, causing thrombosis, tissue necrosis, and painful, nonhealing skin ulcerations. The preponderance of cases occurs in patients undergoing dialysis due to endstage renal disease. Prognosis is generally poor, with one-year mortality ranging from $45 \%$ to $80 \%{ }^{1,2}$. A recent report noted that even among nondialysis patients, renal function was moderately to severely impaired in 69\% [glomerular filtration rate (GFR) $<40$ $\mathrm{ml} / \mathrm{min}]^{1}$. Autoimmune or inflammatory conditions were present in $60 \%$, including systemic lupus erythematosus (SLE), polymyositis, sarcoidosis, hepatitis, ulcerative colitis, rheumatoid arthritis, Sjögren's syndrome, and pemphigus. Various other risk factors are documented, including hyperparathyroidism, elevated serum calcium and phosphate, hypoalbuminemia, obesity, diabetes mellitus, and female sex, and use of warfarin, vitamin D3 analogs and calcium-containing phosphate binders ${ }^{1,2}$.

Couto, et al described a patient with secondary hypoparathyroidism due to vitamin D deficiency, with low calcium/phosphorus product, who developed calciphylaxis in the absence of endstage renal disease ${ }^{3}$. Case reports of calciphylaxis with normal calcium/phosphorus product as well as normal renal function are limited. We describe a case of calciphylaxis in the setting of normal renal function, in a patient with SLE, secondary hyperparathyroidism due to vitamin D deficiency, and normal calcium/phosphorus product.

A 76-year-old African American woman presented to hospital complaining of worsening severe pain, weight loss, fever, night sweats, and chills. Three months previously she first noted painful lesions near her hips and inner thighs. Initial outpatient punch biopsies showed lipophagic fat necrosis without calcification, the differential favoring lupus panniculitis. The wounds showed limited healing on a course of topical and oral steroids.

Medical history included hypertension, atrial fibrillation, SLE (antinuclear antibodies $54 \mathrm{U} / \mathrm{ml}$, ribonucleoprotein $245 \mathrm{AU} / \mathrm{ml}$, anti-Smith 115 $\mathrm{AU} / \mathrm{ml}$ ), breast cancer status post-lumpectomy and radiation therapy, diverticulosis, and osteoarthritis. Surgical history included bilateral total knee arthroplasties. Medications were alendronate, dicyclomine, fluoxetine, furosemide, gabapentin, hydrocodone/acetaminophen, lidocaine oint- ment, lorazepam, metoprolol XL, omeprazole, senna/docusate, verapamil ER, warfarin, zolpidem, and a multivitamin

Examination revealed multiple $4 \mathrm{~cm}$ by $6 \mathrm{~cm}$ ulcers with central eschars on the thighs (Figure 1). Laboratory data revealed white blood cell count 3.8 thousand $/ \mu \mathrm{l}$, hemoglobin $9.2 \mathrm{~g} / \mathrm{dl}$, hematocrit $31 \%$, blood urea nitrogen $10 \mathrm{mg} / \mathrm{dl}$, creatinine $0.87 \mathrm{mg} / \mathrm{dl}$, GFR $>60 \mathrm{ml} / \mathrm{min} / 1.73 \mathrm{~m}^{2}$, and calcium $8.5 \mathrm{mg} / \mathrm{dl}$. Baseline laboratory results before admission were albumin $3.4 \mathrm{~g} / \mathrm{dl}$ and phosphorus $2.8 \mathrm{mg} / \mathrm{dl}$. Given concerns about weight loss, the investigations included computed tomography and bone scan, and positron emission tomography scan, which were negative for malignancy.

Dermatology and rheumatology specialists recommended starting prednisone $60 \mathrm{mg}$ on Day 5, although this was soon tapered to $30 \mathrm{mg}$. A deep tissue biopsy was discussed, but not performed until Day 15, and showed calciphylaxis (Figure 2). Plaquenil was added, and prednisone was tapered to $10 \mathrm{mg}$. On Day 18 laboratory results revealed calcium $7.9 \mathrm{mg} / \mathrm{dl}$ (albumin-corrected $9.1 \mathrm{mg} / \mathrm{dl}$ ), phosphorus $2.7 \mathrm{mg} / \mathrm{dl}$, albumin $2.5 \mathrm{~g} / \mathrm{dl}$, 25-hydroxy vitamin D $22.7 \mathrm{ng} / \mathrm{ml}$ (reference 32-100), and 1,25-hydroxy vitamin D $30.6 \mathrm{pg} / \mathrm{ml}$ (reference 15.9-55.6), and on Day 19 intact parathyroid hormone $121.4 \mathrm{pg} / \mathrm{ml}$ (reference 14-72), despite the patient taking calcium/vitamin D supplement from Days 10 to 20. On Day 22 she was switched from warfarin to enoxaparin for atrial fibrillation.

Parathyroidectomy was discussed but not pursued, as serum calcium concentrations were normal. The decision was made to transfer care to an outside facility more familiar with nonuremic calciphylaxis; the patient's response to treatment is unknown.

Calciphylaxis in patients without renal impairment occurs rarely. A review by Nigwekar, et al of 36 nonuremic cases included only one occurrence of vitamin D deficiency and no patient with $\mathrm{SLE}^{4}$. Our case, along with that of Couto, et al, represents the rare occurrence of calciphylaxis in a patient with secondary hyperparathyroidism due to vitamin D deficiency. The calcium/phosphate product differed in these cases, but it is well known that serum calcium and phosphate levels do not correlate to disease severity $^{1,2}$. To our knowledge, this also represents the first case of calciphylaxis occurring in a patient with SLE and normal renal function.

The exact cause of our patient's disease is unknown. Several other risk factors were present, including female sex, obesity, and warfarin use. She also had a history of breast cancer. However, she was not treated with chemotherapy, and an extensive investigation ruled out metastatic disease.

Many physicians are not familiar with nonuremic cases of calciphylax-

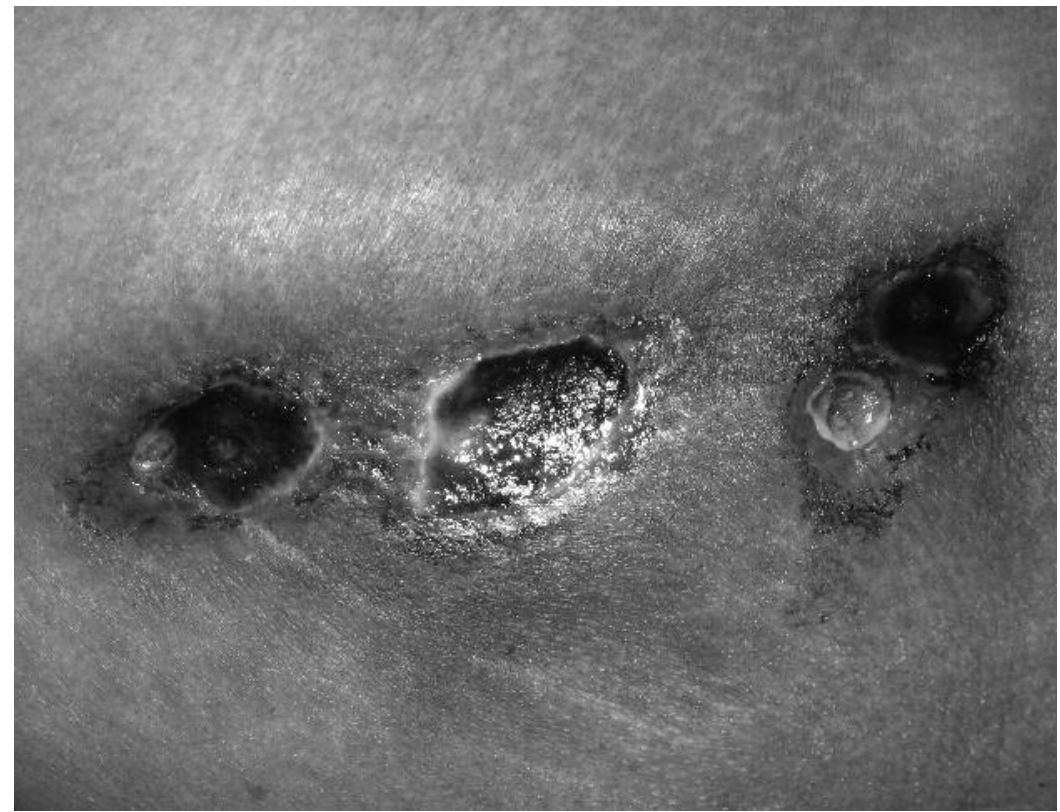

Figure 1. Multiple $4 \mathrm{~cm}$ by $6 \mathrm{~cm}$ ulcers with central eschars on the thighs. 


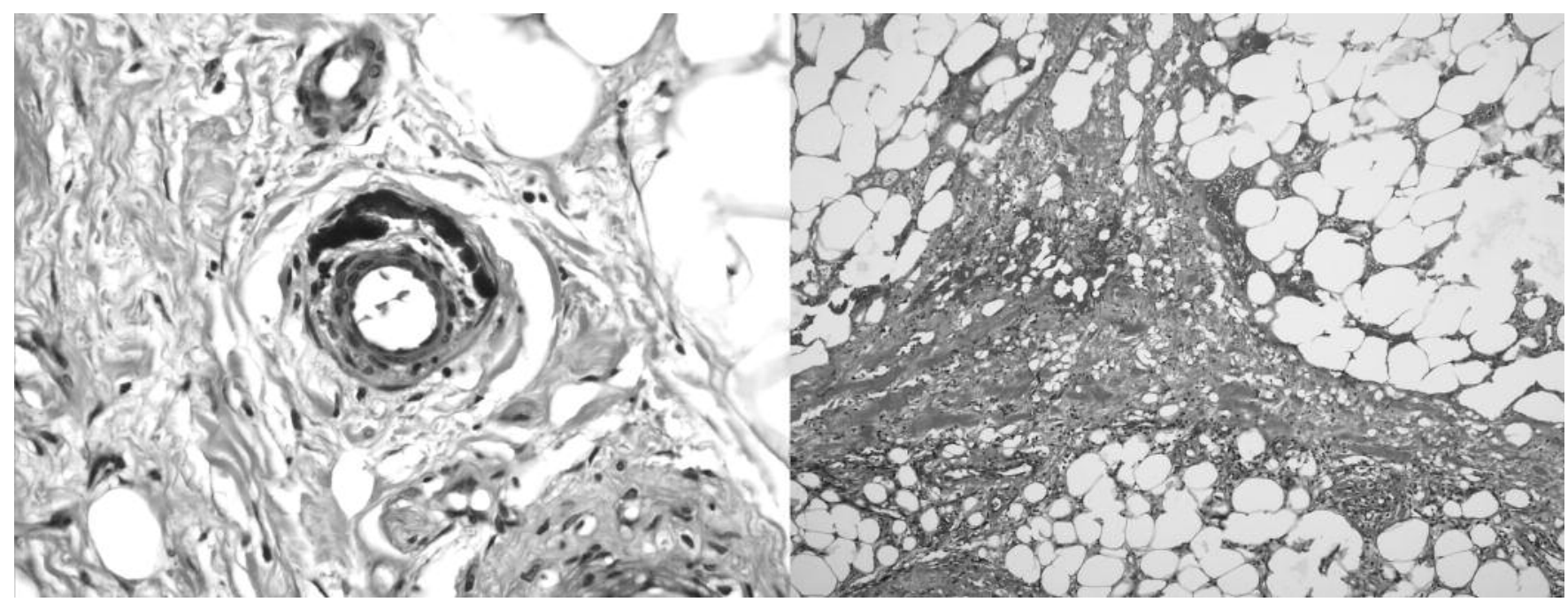

Figure 2. A deep tissue biopsy sample reveals calciphylaxis. H\&E stain; original magnification left 10×, right $4 \times$.

is. It required a protracted hospital stay, numerous tests, and collaborative management from various specialties to reach a diagnosis for this patient. Although prompt diagnosis is important, in order to modify risk factors, clear guidelines for treatment are lacking. Varying success rates exist for parathyroidectomy, surgical debridement, and hyperbaric oxygen therapy $^{1,2}$. Recently, sodium thiosulfate has been used, particularly in a patient with normal renal function ${ }^{5}$. We add this case to the short list of reports of calciphylaxis occurring in the absence of renal disease, hoping to better define the disease etiology and promote awareness.

JOSEPH JOHN ZECHLINSKI, BS; JOEL R. ANGEL, MD, Department of Medicine, Froedtert Hospital, Medical College of Wisconsin, Milwaukee, Wisconsin, USA. Address correspondence to J.J. Zechlinski;

E-mail: jzechlin@mcw.edu

Special thanks to Dr. Joseph Shaker, Department of Medicine, Medical College of Wisconsin, for reviewing the manuscript. Thanks to Dr. Jose Plaza, Department of Pathology, Medical College of Wisconsin, for providing histology figures.

\section{REFERENCES}

1. Weenig RH, Sewell LD, Davis MD, McCarthy JT, Pittelkow MR. Calciphylaxis: natural history, risk factor analysis, and outcome. J Am Acad Dermatol 2007;56:569-79.

2. Meissner M, Gille J, Kaufmann R. Calciphylaxis: no therapeutic concepts for a poorly understood syndrome? J Dtsch Dermatol Ges 2006; 4:1037-44.

3. Couto F, Chen H, Blank R, Drezner M. Calciphylaxis in the absence of end-stage renal disease. Endocr Pract 2006;12:406-10.

4. Nigwekar SU, Wolf M, Sterns RH, Hix JK. Calciphylaxis from nonuremic causes: a systematic review. Clin J Am Soc Nephrol 2008;3:1139-43.

5. Hackett BC, McAleer MA, Sheehan G, Powell FC, O'Donnell BF. Calciphylaxis in a patient with normal renal function: response to treatment with sodium thiosulfate. Clin Exp Dermatol 2009;34:39-42.

J Rheumatol 2009;36:10; doi:10.3899/jrheum.090252 